\title{
Resíduos Sólidos: Percepções de Alunos do Ensino Fundamental
}

\author{
Solid Waste: Perceptions of Elementary School Students \\ Caren Cristiane de Castro Stangherlin', Suzimary Specht ${ }^{2}$ \\ ' Gestora Ambiental, Universidade Federal de Santa Maria, Santa Maria, Brasil. \\ ${ }^{2}$ Docente Curso Superior de Tecnologia em Gestão Ambiental, Universidade Federal de Santa Maria, Santa Maria, Brasil.
}

\section{Resumo}

Este estudo tem como objetivo estimular, alunos da faixa etária dos nove aos onze anos, através de atividades de educação ambiental, a perceberem a importância de se refletir e agir sustentavelmente em prol do meio ambiente, especialmente sobre a questão dos resíduos sólidos. As atividades foram realizadas em duas turmas de $4^{\circ}$ e $5^{\circ}$ ano, na Escola Estadual Bom Conselho, no município de Silveira Martins, RS, onde foram abordados os temas: resíduos sólidos e orgânicos, separação dos resíduos, compostagem, reutilização, reciclagem e a importância do papel dos catadores de resíduos sólidos. As atividades desenvolvidas instigaram os alunos a perceberem a importância de repensarem sobre os resíduos que produzem e como os descartam, bem como da necessidade de ser dado um destino final adequado e sustentável aos resíduos sólidos.

\begin{abstract}
This study aims to estimulate students from nine to eleven years old throught environmental education activities, to understand the importance on reflecting and acting sustainably in favor of environment, specially about the issue of solid residues. The environmental education activities were realized in two groups, the 4th and 5th class at Escola Estadual Bom Conselho, in Silveira Martins city, Rio Grande do Sul state, which the discussed topics were: solid and organic residue, residues separation, composting, reutilization and recycling, remembering the importance of the scavengers of solid residues. The activities instigated students to realize the importance of rethink about their residues and the way they discard it, and the necessity on giving an appropriate and sustainable final destination for the solids residues.
\end{abstract}




\section{INTRODUÇÃO}

O crescimento populacional, o crescimento desordenado da maioria das cidades, o aumento do consumo de produtos embalados e a rápida substituição dos eletrônicos por novos modelos imbuídos de novas tecnologias vem gerando uma problemática: a geração de grandes volumes de resíduos sólidos. Por consequência, a disposição destes resíduos sólidos tem se tornado um dos maiores entraves enfrentados no gerenciamento urbano, pois, quando dispostos de forma inadequada causam sérios danos ao meio ambiente.

Os resíduos sólidos são provenientes da mistura de materiais ou restos destes, advindos dos diversos tipos de atividades humanas, que são descartados por não possuírem utilidade ou valor financeiro. Eles podem ser classificados sob diversos critérios, como a natureza física, a composição química, a origem, os riscos potenciais ao meio ambiente, etc. A produção e a disposição dos resíduos constitui um dos maiores problemas ambientais do mundo (COSTA, 2005).

A classificação mais usual é segundo a origem, podendo o resíduo ser classificado como: domiciliar, de limpeza urbana, sólidos urbanos, comerciais, de prestadores de serviços, de serviços públicos, de saneamento básico, industriais, de serviços de saúde, de construção civil, agrossilvipastoris, de serviços de transportes e de mineração (BRASIL, 2010).

A forma de disposição dos resíduos sólidos constitui um grande problema ambiental do Brasil, agravando a poluição das águas, do ar e do solo. Estes são dispostos em: lixões, aterros sanitários controlados, aterros sanitários não controlados, tratamento por incineração, tratamento por reciclagem e tratamento por compostagem (COSTA, 2005). Segundo dados do IBGE em 2008, 50,8\% dos resíduos sólidos foram destinados a vazadouros a céu aberto, 22,5\% a aterros controlados e $27,7 \%$ a aterros sanitários. Porém, contra dados do IBGE apontam que este cenário vem mudando lentamente, pois houve uma expansão no destino dos resíduos para aterro sanitário passando de 17,3\% dos municípios, em 2000, para 27,7\%, em 2008.

Cabe ressaltar, que a produção de resíduos sólidos resulta de um modelo produtivo baseado fortemente no consumo, pois livrar-se das coisas, substituí-las, renová-las se torna tão ou mais importante do que a mera posse ou uso. Consumidores não se importam de destinar à lixeira tudo o que já tenha cumprido sua função, seu tempo de uso (CUNHA, 2009). Uma das formas de reverter este processo danoso ao meio ambiente é a reutilização e a reciclagem dos resíduos sólidos.

A reutilização de materiais, segundo Grippi (2006) é um processo bem antigo, sendo que a partir do final do século XX, além da reutilização, também passou a ser muito importante a reciclagem. Segundo o autor, alguns dados mostram que no início do século XX o papel já era reciclado em alguns países do mundo, incluso o Brasil, onde a reciclagem do papel teve início a partir de 1920, com a industrialização.

A reciclagem "é um processo de transformação dos resíduos sólidos que envolvem a alteração de suas propriedades físicas, físico-químicas ou biológicas, com vistas à transformação em insumos ou novos produtos" (BRASIL, 2010, p.2). Os materiais recicláveis são classificados em papel, metal, plástico e vidro, incluindo os materiais orgânicos que são reciclados através da compostagem. Apesar da reciclagem ser um meio importante de reduzir a quantidade de resíduos, está longe de solucionar o problema. Existem diversos outros tipos de materiais descartados que não podem ser reciclados, como, por exemplo, fraldas, absorventes, guardanapos, papel higiênico, isopor, entre outros (BRITTO, 2010).

No entanto, há um enorme desperdício de materiais recicláveis, e segundo Zveibil (2001, p. 119),

"o tratamento mais eficaz é o prestado pela população quando está empenhada em reduzir a quantidade de lixo, evitando o desperdício, reaproveitando os materiais, separando os recicláveis em casa ou na própria fonte e se desfazendo do lixo que produz de maneira correta".

A questão dos resíduos sólidos é um grande problema a ser enfrentado por todos os cidadãos que habitam esse planeta. E uma das formas de mudar este cenário é a sensibilização das pessoas, é aguçar a percepção em prol do meio ambiente. Nos diversos momentos de nossa vida, aprendemos e representamos a realidade de um modo particular, pois as coisas são vistas conforme nossas possibilidades intelectuais e emocionais. Este fato é resultado do processo evolutivo do ser humano, que influencia e é influenciado pelas histórias que o rodeiam (BOSSA; OLIVEIRA, 1996).

A partir disso, pode-se definir o conceito de percepção, que, para Coimbra (2004), é um subs- 
tantivo que se aplica ao ato, ao processo de perceber, assim como o resultado dessas ações, ou seja, perceber um fato, um fenômeno ou uma realidade. É o primeiro passo no processo do conhecimento, no qual dependem dele aspectos teóricos e aplicações práticas.

Já para Hammes (2012, p. 171), "a percepção é um processo cognitivo de apreensão de uma informação ou estímulo presente no ambiente próximo ao indivíduo", sendo um processo inconsciente, mas que auxilia na conscientização.

A percepção é desenvolvida através dos sentidos, sendo diferente em cada indivíduo, pois o significado que os estímulos sensoriais despertam é a forma que distingue como cada indivíduo compreende a realidade em que está inserido, portanto são valores atribuídos conforme a cultura, educação, classe social, religião, sexo, idade, história, atitudes e atribuições do meio ambiente (OLIVEIRA; CORONA, 2008).

Porém, algumas atividades perceptivas são comportamentos observáveis, como o conhecimento visual, olfativo, auditivo, tátil, etc., que intervêm na interpretação. Estes sentidos são muito explorados pelas crianças, que podem ser utilizados para exercitar as questões ambientais através dos recursos da natureza, utilizando-se de cores, números e conceitos de abstrato e concreto (HAMMES, 2012).

Segundo Coimbra (2004), a percepção do meio ambiente é, a uma só vez, processo e resultado. Como processo é o ponto de partida para o conhecimento ambiental e como resultado pode significar todo o conhecimento adquirido a respeito do meio ambiente.

Desta forma, é de fundamental importância identificar a forma como os seres humanos percebem o ambiente em que vivem, para uma melhor compreensão da relação que desenvolvem neste local (BOING, 2007). Uma das alternativas para potencializar esta compreensão é a educação ambiental, que no Brasil foi normatizada através da Lei $\mathrm{n}^{\circ}$ 9.795, de 27 de janeiro de 1999, que dispõe sobre a Educação Ambiental e institui a Política Nacional de Educação Ambiental sendo que,

entende-se por educação ambiental os processos por meio dos quais o indivíduo e a coletividade constroem valores sociais, conhecimentos, habilidades, atitudes e competências voltadas para a conservação do meio ambiente, bem de uso comum do povo, essencial à sadia qualidade de vida e sua sustentabilidade (BRASIL, 1999).

A educação ambiental visa inserir as pessoas no contexto ambiental e permitir que elas sejam capazes de vislumbrar a solução dos problemas. Esta deve ser oferecida para os indivíduos de todas as faixas etárias, em todos os níveis, na educação formal e informal, nas escolas, universidades, comunidades, etc., proporcionando a todos conhecimentos, valores e atitudes para preservar e proteger o meio ambiente (BRITTO, 2010).

É notório que parte da população não colabora com as questões ambientais devido à falta de informação. Logo não poderá haver conservação e nem preservação ambiental sem a educação, visto que esta constrói no indivíduo e em grupos sociais uma consciência de mudança de comportamento e atitudes (GRIPPI, 2006).

Desta forma, toda a sociedade precisa educar suas ações, mudar seus hábitos, pensar globalmente, mudar de atitude. E esta mudança deve começar com as crianças, pois é nesta fase que se formam os "adultos do futuro", aprendendo que a responsabilidade é de todos e que seus atos trazem consequências para toda a humanidade (NARCIZO, 2009). A educação tem vários significados, e como aponta Pelicioni (2004), educação significa conduzir, liderar, puxar para fora; baseado na ideia de que todos os seres humanos nascem com o mesmo potencial, que deve ser desenvolvido no decorrer da vida. Porém, o desenvolvimento é mais intenso na infância.

Dentre as faixas etárias que compõem a infância, uma que chama a atenção é a de crianças entre os 9 e 10 anos, que, segundo Netto (2009) e Araújo (2013), possuem características peculiares tais como: senso crítico em estado de expansão, coordenação visual e motora semelhante a de um adulto, interesse em experimentar e explorar coisas novas, capacidade para assumir maiores responsabilidades, pensamento crítico e maior sociabilidade.

Para Bossa e Oliveira (1996), as experiências vividas pelas crianças de 7 a 11 anos decidirão parte de suas vidas adultas, ou seja, os relacionamentos sociais são estruturantes. Ainda segundo os autores, elas apresentam interesses, preocupações, necessidades e conflitos, sendo que nesta fase elas possuem um nível elevado de atenção e concentração, passam a compreender o pensamento do outro, são capazes de desenvolver problemas mentalmente, aprendem a competir e a compartilhar. A 
partir deste momento, os colegas, os professores e o trabalho escolar passam a atuar na formação da personalidade da criança.

Tendo por pressuposto este cenário, o objetivo deste trabalho é estimular, alunos da faixa etária dos nove aos onze anos, através de atividades de educação ambiental, a perceberem a importância de se refletir e agir sustentavelmente em prol do meio ambiente, especialmente sobre a questão dos resíduos sólidos.

\section{METODOLOGIA}

Este trabalho foi realizado na Escola Estadual Bom Conselho, na cidade de Silveira Martins, no estado do Rio Grande do Sul, com alunos do $4^{\circ}$ e $5^{\circ}$ anos, com a faixa etária entre nove e onze anos. Esta escola é estadual e abrange o ensino fundamental e ensino médio. O projeto foi desenvolvido em um dia letivo, de quatro horas/aula, com cada uma das turmas. Participaram 14 e 16 alunos do $4^{\circ}$ e $5^{\circ}$ ano, respectivamente, além da professora responsável por cada turma. Nas duas turmas, foram propostas as mesmas atividades.

Primeiramente, foi conversado com as professoras das turmas, a fim de averiguar se já havia sido trabalhada a temática sobre resíduos sólidos com os alunos. Diante da afirmativa que os mesmos já tiveram um contato inicial com a temática, foi elaborado um roteiro de atividades a serem aplicados a estes.

Inicialmente, em cada uma das turmas, foi feito um diagnóstico com os alunos, onde estes foram questionados sobre a percepção e o conhecimento que possuíam sobre resíduos sólidos. Foi verificado, nas duas turmas, que os alunos desconheciam esta designação dada ao "lixo". Na sequência foi abordada a diferença entre resíduo sólido e orgânico e como deve ser feita a separação dos resíduos nas residências, e foi questionado se as famílias participavam do projeto da coleta seletiva de Silveira Martins ${ }^{1}$. Após, foi abordada a importância da compostagem com os resíduos orgânicos.

A partir deste primeiro momento foi apresentado um vídeo com duração de 12:52 minutos, que é um recorte do documentário Lixo Extraordinário, de Vik Muniz, lançado no ano de 2010, gravado em um dos maiores aterros sanitário do mundo, localizado em Jardim Gramacho, no bairro de Duque de Caxias, no Rio de Janeiro. Este recorte mostra, através de depoimentos, a vida dos catadores de materiais recicláveis, seus problemas, medos, anseios, tristezas, sonhos e esperanças. A partir disto, foi feita uma conversa com os alunos para averiguar a percepção deles sobre a questão e o que mais chamou a sua atenção.

No terceiro momento foi proposta uma atividade prática de reutilização de resíduos sólidos, com potencial à reciclagem, para a confecção de artesanato. Por fim, foi proposto que cada aluno fizesse um mini texto, relatando sua percepção sobre a questão dos resíduos sólidos e das atividades de educação ambiental desenvolvidas ao longo da aula.

\section{RESULTADOS E ANÁLISE}

No diagnóstico feito com os alunos do $4^{\circ}$ e $5^{\circ}$ anos, pode-se perceber que, em ambas as turmas, nenhum aluno sabia o que era o termo "resíduo sólido". Para eles, os resíduos, tanto recicláveis, quanto orgânicos eram conhecidos como "lixo". Portanto, foi-lhes explicado que resíduo sólido, conforme Costa (2005) é toda mistura de materiais ou restos destes, advindos dos diversos tipos de atividades humanas, que são descartados por não possuírem utilidade ou valor financeiro.

Percebeu-se que os alunos sabiam a diferença entre resíduo "lixo" sólido e orgânico, e citaram exemplos como:

"lixo seco é garrafa pet, plástico e lixo orgânico é resto de comida, cascas de frutas".

\footnotetext{
${ }^{1}$ Projeto de extensão realizado pela UDESSM em parceria com a Prefeitura Municipal de Silveira Martins, que tem por objetivo implementar a coleta seletiva na área urbana do município e conscientizar a população sobre a problemática da destinação inadequada dos resíduos sólidos e orgânicos.
} 
Constatou-se que somente duas das famílias dos alunos do $4^{\circ}$ ano separam os resíduos em suas residências. Já no $5^{\circ}$ ano, este índice é maior, com cinco famílias. Sobre a questão da compostagem os alunos já tinham conhecimento, o que pode ser apontado pela fala a seguir:

"fazer compostagem é abrir um buraco na terra e colocar os restos de comida e cascas de frutas e depois tapar com terra, para os alimentos se decomporem e virarem adubo".

No $4^{\circ}$ ano, quatro alunos falaram que fazem compostagem ou que algum familiar seu faz. Porém, no $5^{\circ}$ ano, ninguém faz e um aluno ainda salientou:

"a gente fazia, mas o meu cachorro ia lá e revirava tudo, então não fizemos mais".

Sobre o projeto da Coletiva Seletiva de Silveira Martins, nenhuma família dos alunos participa, sendo que todos afirmaram desconhecer o projeto. Após esta constatação chamou a atenção, que mesmo não provendo de coleta seletiva municipal implantada para todos os habitantes, algumas famílias de alunos praticam a seleção de resíduos, como foi apontado anteriormente.

Durante a apresentação do vídeo com os alunos do $4^{\circ}$ ano, alguns relataram que já tinham ouvido falar do documentário Lixo Extraordinário. Mas, no decorrer do vídeo, todos ficaram muito atentos e a maioria perplexa com a situação ali mostrada. Ao final, todos os alunos deram suas opiniões sobre o que havia lhes chamado mais atenção e houve alguns relatos interessantes, como:

"o filme é triste e muito interessante";

"é educativo e importante para aprender a separar o lixo";

"mostrou a realidade da sobrevivência no lixão";

"foi bom para aprender a separar lixo seco do orgânico";

"mostrou que temos que reaproveitar, ocupar todos os materiais".

Notou-se que com esta turma o documentário teve mais impacto e deixo-os mais pensativos sobre o assunto.

Durante a apresentação do documentário com o $5^{\circ}$ ano, notou-se que, nos primeiros momentos, alguns alunos ficaram dispersos e outros começaram a rir, enquanto um catador estava dando seu depoimento. Como aponta Keil (2005), a grande maioria dos catadores de material reciclável suporta preconceitos, ao serem confundidos com mendigos e vadios, e sofrem repressão e desprezo. Fato este que não deveria ocorrer, pois eles possuem um papel de grande relevância tanto no âmbito social como ambiental, pois realizam um serviço público que deveria ser de inteira responsabilidade do governo local.

Após o final do documentário foi feita uma reflexão com os alunos sobre a importância do trabalho dos catadores para o meio ambiente. E no segundo momento foi enfatizada a questão econômica e social, quando foi explicado aos alunos que a catação de resíduos sólidos é uma profissão já regulamentada por lei, Como mostra a Classificação Brasileira de Ocupações (2002), os catadores de material reciclável foram normatizados como categoria profissional, sendo exercida por profissionais que se organizam de forma autônoma ou em cooperativas. Além disso, o acesso ao trabalho é livre, sem exigência de escolaridade (MTECBO, 2002).

Cabe salientar que após o término do vídeo foi possível perceber que muitos alunos ficaram surpresos com a situação dos catadores de materiais recicláveis e relataram:

"é uma situação triste";

"é importante separar os materiais que são recicláveis".

"esta é uma profissão como outra qualquer";

e a menina filha de um catador, completou:

"meu pai consegue sustentar a gente assim".

A partir destes relatos foi realizado um debate sobre a importância da separação dos resíduos pelos cidadãos nos seus domicílios, pois os resíduos sólidos são materiais de trabalho e promovem 
sustento às pessoas que trabalham com catação.

Quando foram propostas as atividades práticas, os alunos do $4^{\circ}$ ano escolheram como material de trabalho garrafas pet, com as quais foram confeccionadas peças de artesanato e brinquedos. Todos os meninos fizeram um vai e vem e as meninas uma flor. Alguns alunos propuseram e criaram também diferentes formas de artesanato como barco, coroa, vaso de flor e carro. Eles também relataram que já reaproveitaram outros materiais, como a caixa de leite tetra pak, para plantar mudas de flor, que já haviam feito na escola uma tartaruga com a garrafa pet e que juntaram casca de lápis para utilizar no presépio de natal (Figura 1).

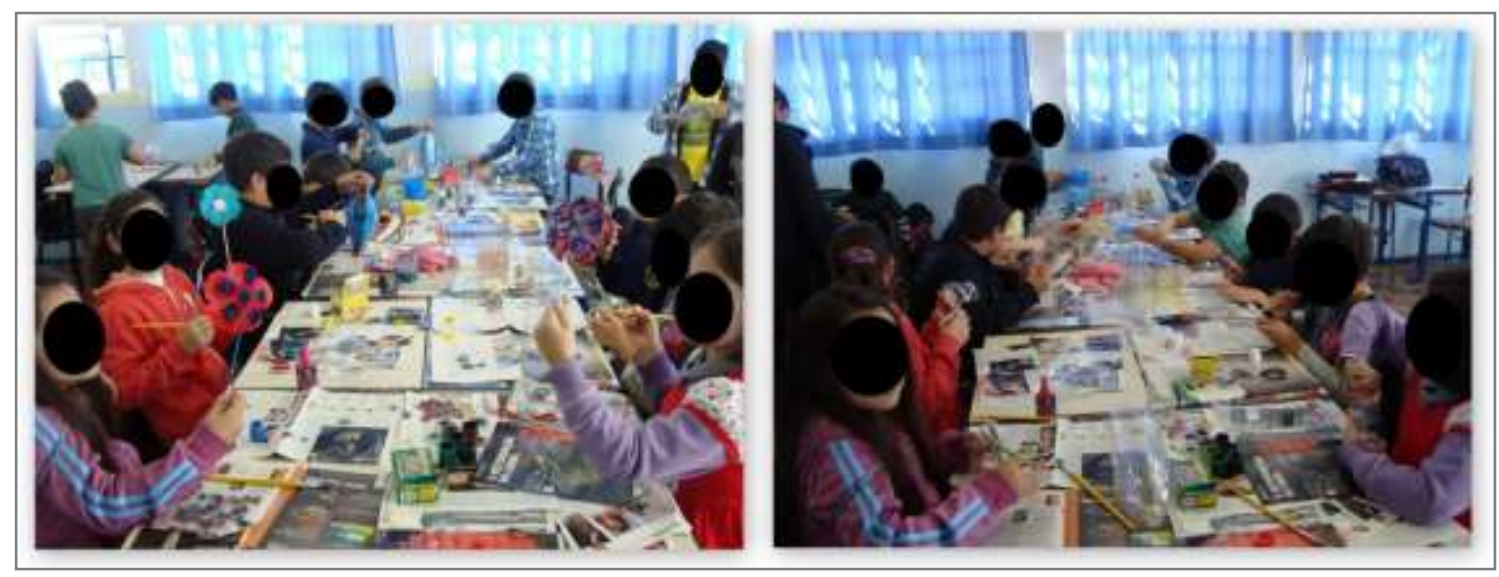

Figura 1 - Confecção de brinquedo através da reutilização de resíduo sólido pelos alunos do $4^{\circ}$ ano da Escola Estadual Bom Conselho, Silveira Martins, RS.

*Foto das autoras.

Pelos comentários dos alunos e pela expressão dos mesmos durante as atividades, foi perceptível que a aula prática foi prazerosa e se mostrou uma ferramenta eficiente de educação ambiental para com a temática dos resíduos. Porém, como aponta Grippi (2006), a reciclagem não pode ser vista como a única solução para os resíduos sólidos, mas deve ser considerada parte de um conjunto de soluções ambientais. Esta afirmação também pode ser aplicada para a questão da reutilização dos resíduos sólidos

Com os alunos do $5^{\circ}$ ano, a atividade prática da confecção do brinquedo vai-e-vem e do artesanato flor também foi divertida e educativa. Os mesmos, ao final das atividades proposta, também comentaram sobre outras ideias de reutilização de materiais recicláveis, especialmente, garrafas pet (Figura 2).

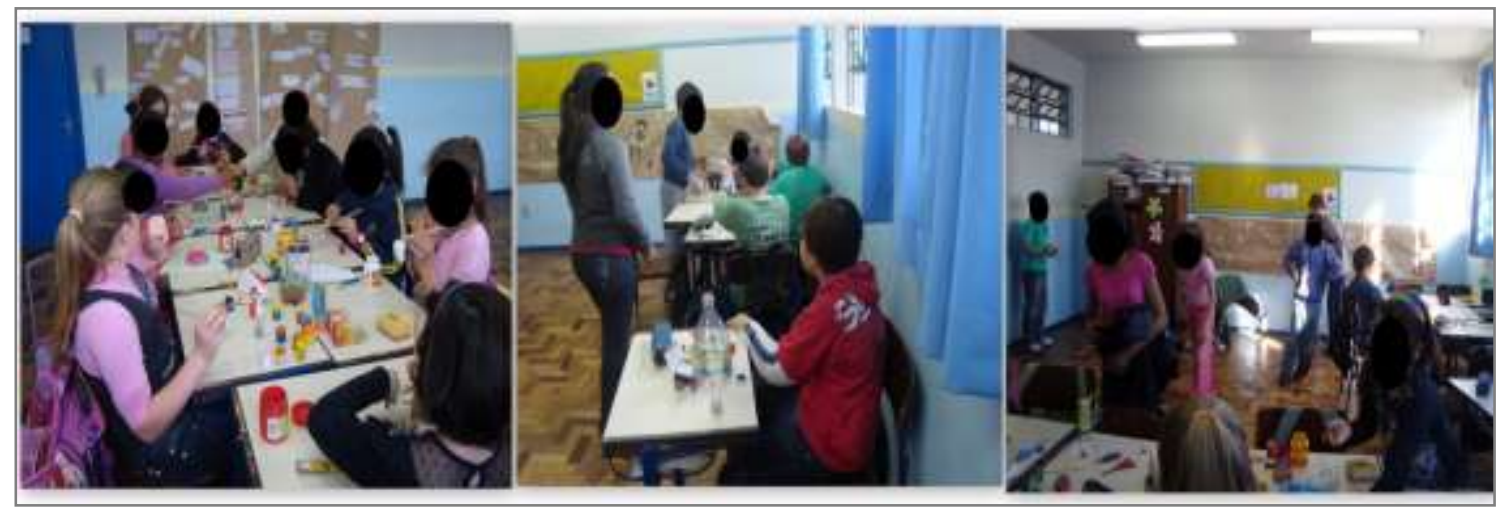

Figura 2 - Confecção de brinquedo através da reutilização de resíduo sólido pelos alunos do $5^{\circ}$ ano da Escola Estadual Bom Conselho, Silveira Martins, RS.

*Foto das autoras. 
Ao produzirem o mini texto (Figura 3), após o final das atividades de educação ambiental, os alunos demonstraram que houve uma mudança de percepção em relação à temática "resíduos". Este aspecto pode ser evidenciado em alguns relatos oriundos dos mini textos escritos pelos alunos.

Turma do $4^{\circ}$ ano:

"eu achei o filme bom para aprender como é a vida no lixão. E eu também achei a aula muito divertida para reocupar o que nós colocamos no lixo";

"eu achei a aula muito legal hoje, o filme, as atividades e os brinquedos que nós fizemos e eu aprendi muita coisa, a reciclar e muitas outras coisas";

"eu achei muito legal e a atividade que nós fizemos é muito engraçada e eu achei o filme triste por causa daquelas pessoas";

"eu achei o filme interessante que devemos utilizar o lixo e botar o lixo no lixo. Eu achei a brincadeira legal e engraçada";

"eu achei legal e divertido porque eu aprendi o que fazer com o lixo reciclável. E fazer brinquedos com o lixo reciclável";

"eu achei o vídeo educativo e triste. Gostei muito dos brinquedos".

Turma do $5^{\circ}$ ano:

"eu gostei, porque é muito legal as palestras sobre reciclagem do lixo, nós temos que cuidar do nosso planeta reciclando, e assim também ajudamos o catadores";

"eu achei muito legal. A gente aprendeu muitas coisas sobre lixo. E é muito importante reciclar o lixo";

"eu achei bom, mas ao mesmo tempo achei que passam sacrifício no lixão. Mas gostei do trabalho da flor";

"as atividades e o vídeo foram muito legal, gostei muito. Vou começar a separar o lixo orgânico do seco";

"eu achei legal e acho que temos que fazer bastante isso para reciclar".

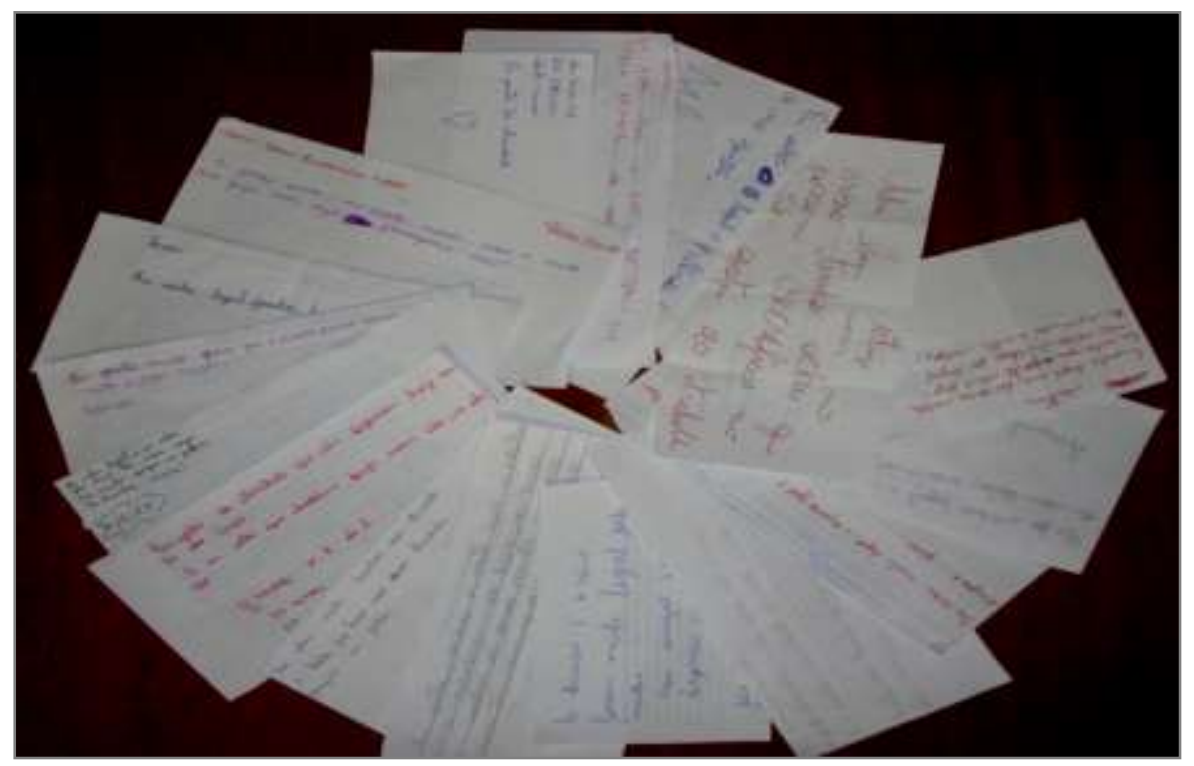

Figura 3 - Mini textos elaborados pelos alunos do $4^{\circ}$ e do $5^{\circ}$ ano da Escola Estadual Bom Conselho, Silveira Martins, RS, sobre sua percepção em relação aos resíduos sólidos após as atividades de educação ambiental.

*Foto das autoras.

Portanto, como afirma Coimbra (2004), a percepção é como cada indivíduo percebe um fato ou um fenômeno. É diferente em cada pessoa, pois é a maneira como cada um compreende a realidade. E como apontam Oliveira e Corona (2008), os valores são atribuídos conforme a cultura, educação, 
classe social, idade, história, entre outros. À vista disso, percebeu-se a diferença entre os relatos, pois cada criança deu ênfase no fato que lhe chamou mais atenção.

\section{CONCLUSÃO}

Quando foi iniciado o trabalho de educação ambiental com os alunos, em ambas as turmas, os mesmos tinham um conhecimento restrito sobre a temática dos resíduos sólidos e preconceito com relação aos catadores. Mas ao final das atividades, a maioria dos alunos demonstraram mudanças de percepção sobre a questão dos resíduos sólidos, principalmente, após a apresentação do vídeo, pois até então alguns estavam considerando as atividades como entretenimento. Este fato foi observado através das falas de algumas crianças, ao dizerem, por exemplo, que iriam começar a fazer a separação dos resíduos em suas residências, que iriam reutilizar alguns materiais, que gostariam que tivessem mais encontros de educação ambiental na escola, etc.

A atividade prática de reutilização de resíduos sólidos, com potencial à reciclagem, teve bastante influência na percepção dos alunos, pois as crianças foram instigadas a repensarem sobre o que descartam e o que poderiam reaproveitar, dando um destino final mais adequado e sustentável aos resíduos sólidos.

Por fim cabe salientar, que os resultados destas atividades não devem se restringir a este momento de sensibilização. Foi buscado potencializar nas crianças formas de mobilização para a questão dos resíduos sólidos, pois as crianças de hoje serão os adultos responsáveis pelas ações no futuro. Portanto, as atividades de educação ambiental poderiam ser pensadas como integrantes do currículo escolar do ensino fundamental e médio, contextualizado em todas as disciplinas, pois as temáticas sobre meio ambiente são transversais e englobam várias áreas do conhecimento.

\section{REFERÊNCIAS}

ARAUJO, R. M. B. de. Características da Criança em Cada Faixa Etária. In: NÚCLEO de apoio cristão. Guarapari - ES. Disponível em:

<http://www.montesiao.pro.br/estudos/crianca/caract_faixaetaria.html>. Acesso em: 10 jan. 2013.

BOING, L. A Percepção Ambiental como Subsídio para a Educação Ambiental: estudo de caso do caminho do Itupava - Paraná. Curitiba, 2007. Disponível em: <http://www.physis.org.br/ecouc/Artigos/Artigo3. pdf $>$. Acesso em: 16 jan. 2013.

BOSSA, N. A.; OLIVEIRA, V. B. de. (Org.). Avaliação Psicopedagógica da Criança de Sete a Onze Anos. 9. ed. Petrópolis, RJ: Vozes, 1996. 182 p.

BRASIL. Lei n. 9.795, de 27 de abril de 1999. Presidência da República - Casa Civil, Brasília, DF, 27 abr. 1999. Disponível em:

<http://www.planalto.gov.br/ccivil_03/Leis/L9795.htm>. Acesso em: 13 jan. 2013.

BRASIL. Lei n. 12.305, de 2 de agosto de 2010. Presidência da República - Casa Civil, Brasília, DF, 2 ago. 2010. Disponível em:

<http://www.planalto.gov.br/ccivil_03/_ato2007-2010/2010/lei/112305.htm>. Acesso em: 13 jan. 2013.

BRITTO, K. K. V. de. Percepção Ambiental sobre a Disposição de Resíduos Sólidos no Bairro Jardim Europa no Município de Foz do Iguaçu - PR. 2010. 58f. Monografia. Curso de em Engenharia Ambiental. União Dinâmica de Faculdades Cataratas, Foz do Iguaçu - PR, 2010.

COSTA, W. D. Depósitos de Resíduos Sólidos e seus Riscos para a Coletividade. In: COURA, J. F. (Org.). 
Geologia na Gestão do Município. Minas Gerais: Singeo/Abge, 2005. p. 133-138.

COIMBRA, J. A. A. Linguagem e Percepção Ambiental. In: JUNIOR, A. P.; ROMÉRO, M. de A.; BRUNA, G. C.; (Ed.). Curso de Gestão Ambiental. São Paulo: Manole, 2004. cap. 15, p. 525- 570.

CUNHA, M. R. R. L. Risco e Consumo: a construção da identidade a partir do lixo. Fragmentos de cultura. Goiânia, v. 19, n. 3/4, p. 185-205, mar./abr. 2009.

GRIPPI, S. Lixo: reciclagem e sua história: guia para as prefeituras brasileiras. 2. ed. Rio de Janeiro: Interciência, 2006.

HAMMES, V. S. Percepção Ambiental. In: HAMMES, V. S (Ed.). Proposta Metodológica de Macroeducação. Brasília, DF: Embrapa, 2012. cap. 1, p. 171-173.

INSTITUTO BRASILEIRO DE GEOGRAFIA E ESTATÍSTICA - IBGE. Disponível em: <

http://www.ibge.gov.br/home/presidencia/noticias/noticia_visualiza.php?id_noticia=1691\&id_pagina=1>. Acesso em: 20 fev. 2013.

KEIL, I. M. (Pesq.). Crianças e Adolescentes no Universo do Lixo. FNPETI - Fórum Nacional de Prevenção e Erradicação do Trabalho Infantil, 2005.

MINISTÉRIO DO TRABALHO E EMPREGO - CBO - Classificação Brasileira de Ocupações. 2002. Disponível em: <http://www.mtecbo.gov.br/cbosite/pages/relatorio/relatorioTemplateWordFamilia.jsf>. Acesso em: 18 jan. 2013.

MOVIMENTO NACIONAL DOS CATADORES DE MATERIAIS RECICLÁVEIS - MNCR. Classificação Brasileira de Ocupações. 2008. Disponível em: <http://www.mncr.org.br/box_2/instrumentos-juridicos/ classificacao-brasileira-de-ocupacoes-cbo>. Acesso em: 20 abr. 2013.

NARCIZO, K. R. dos S. Uma Análise sobre a Importância de Trabalhar Educação Ambiental nas Escolas. Revista eletrônica do Mestrado em Educação Ambiental. Rio Grande, v. 22, p. 86-94, jan-jul. 2009.

NETTO, M. H. T. A Mente de 9 a 11 anos. In: Artigos de Psicologia. 2009. Disponível em: <http://artigosdepsicologia.wordpress.com/2009/07/06/a-mente-de-9-a-11-anos/ >. Acesso em: 10 jan. 2013.

OLIVEIRA, K. A. de.; CORONA, H. M. P. A Percepção Ambiental como Ferramenta de Propostas Educativas e de Políticas Ambientais. Revista Científica ANAP- Amigos da Natureza - Brasil, Paraná, n. 1, jul. 2008. Disponível em: <http://www.amigosdanatureza.org.br/revista/artigos/6f8ee05efd7824581c7552f541bed373. pdf>. Acesso em: 10 jan. 2013.

PELICIONI, M. C. F. Fundamentos de Educação Ambiental. In: JUNIOR, A. P.; ROMÉRO, M. de A.; BRUNA, G. C.; (Ed.). Curso de Gestão Ambiental. São Paulo: Manole, 2004. p. 459-483.

ZVEIBIL, V. Z. (Coord.) Manual de Gerenciamento Integrado de Resíduos Sólidos. Rio de Janeiro: IBAM, 2001. p. 119. 